Article

\title{
Fructose-Rich Diet Is a Risk Factor for Metabolic Syndrome, Proximal Tubule Injury and Urolithiasis in Rats
}

\author{
Mariusz Flisiński ${ }^{1, *(\mathbb{D}}$, Andrzej Brymora ${ }^{1}$, Natalia Skoczylas-Makowska ${ }^{2}$, Anna Stefańska ${ }^{3}(\mathbb{D})$ and \\ Jacek Manitius ${ }^{1}$ \\ 1 Department of Nephrology, Hypertension and Internal Medicine, Collegium Medicum in Bydgoszcz, \\ Nicolaus Copernicus University in Torun, 85-094 Bydgoszcz, Poland; andrzej.brymora@cm.umk.pl (A.B.); \\ synowie2@o2.pl (J.M.) \\ 2 Department of Clinical Pathology, Collegium Medicum in Bydgoszcz, Nicolaus Copernicus University \\ in Toruń, 85-094 Bydgoszcz, Poland; n.makowska@cm.umk.pl \\ 3 Department of Laboratory Medicine Collegium Medicum in Bydgoszcz, Nicolaus Copernicus University \\ in Toruń, 85-094 Bydgoszcz, Poland; zuzanna@cm.umk.pl \\ * Correspondence: mflisinski@cm.umk.pl; Tel.: +48-52-5854551
}

\section{check for}

updates

Citation: Flisiński, M.; Brymora, A.; Skoczylas-Makowska, N.; Stefańska, A.; Manitius, J. Fructose-Rich Diet Is a Risk Factor for Metabolic Syndrome, Proximal Tubule Injury and Urolithiasis in Rats. Int. J. Mol. Sci. 2022, 23, 203.

https://doi.org/10.3390/ ijms23010203

Academic Editors: Simona Bungau and Tapan Behl

Received: 6 December 2021

Accepted: 22 December 2021

Published: 24 December 2021

Publisher's Note: MDPI stays neutral with regard to jurisdictional claims in published maps and institutional affiliations.

Copyright: (C) 2021 by the authors. Licensee MDPI, Basel, Switzerland. This article is an open access article distributed under the terms and conditions of the Creative Commons Attribution (CC BY) license (https:// creativecommons.org/licenses/by/ $4.0 /)$.

\begin{abstract}
Excessive consumption of fructose (FR) leads to obesity, metabolic syndrome (MS) and insulin resistance, which are known risk factors for kidney stones. The epidemiological study has suggested the association between fructose consumption and urolithiasis, but the precise mechanism is still not well understood. Male Wistar rats were assigned for 8 weeks to three groups with different FR content in diet: RD $(n=5)$-regular diet with a FR $<3 \%$; F10 $(n=6)$-regular diet with an addition of $10 \%$ Fr in drinking water; F60 $(n=5)-60 \%$ FR as a solid food. Serum concentration of FR, creatinine (Cr), insulin (Ins), triglycerides (Tg), homocysteine (HCS), uric acid (UA), calcium (Ca), phosphate $(\mathrm{Pi})$, magnesium $(\mathrm{Mg})$ and sodium $(\mathrm{Na})$ were measured. Based on $24 \mathrm{~h}$ urine collection the following tests were performed: urine $\mathrm{pH}$, proteinuria (PCR), excretion of N-Acetyl-(D)-Glucosaminidase (NAG), monocyte chemoattractant protein (MCP-1), uric acid (uUAEx), phosphate (uPiEx), calcium ( $\mathrm{uCaEx})$, magnesium (uMgEx) and sodium (uNaEx). The creatinine clearance $(\mathrm{CrCl})$ was calculated. Calcium deposits in kidney sections were examined using hematoxylin and eosin (HE) and von Kossa stains. The rats on F10 and F60, as compared to the RD diet, showed a tendency for lower $\mathrm{CrCl}$, higher HCS level and some features of MS as higher Ins and TG levels. Interestingly, F10 (fluid) versus F60 (solid) diet led to higher serum Ins levels. F10 and F60 versus RD demonstrated higher urinary excretion of MCP-1 and NAG which were suggestive for inflammatory injury of the proximal tubule. F10 and F60 as compared to RD showed significantly lower uUAEx, although there were no differences in clearance and fractional excretion of UA. F60 versus RD induced severe phosphaturia $(>30 \times)$ and natriuria $(4 \times)$ and mild calciuria. F10 versus RD induced calciuria $(3 \times)$, phosphaturia $(2 \times)$ and mild natriuria. Calcium phosphate stones within the tubules and interstitium were found only in rats on FR diet, respectively, in two rats from the F10 group and another two in the F60 group. The rats which developed stones were characterized by significantly higher serum insulin concentration and urinary excretion of calcium and magnesium. A fructose-rich diet may promote development of calcium stones due to proximal tubule injury and metabolic syndrome.
\end{abstract}

Keywords: fructose-rich diet; metabolic syndrome; proximal tubule injury; urolithiasis; rats

\section{Introduction}

Fructose (FR) is a monosaccharide occurring naturally in fruits and honey. Its consumption has been increasing dramatically worldwide primarily due to the addition of sucrose (a disaccharide containing 50\% fructose and 50\% glucose) and high-fructose corn syrup (HFCS) to foods and soft drinks. It is estimated that the FR consumption has increased by $2000 \%$ in the US since HFCS introduction in 1967 [1]. Today, the mean FR intake is about $74 \mathrm{~g} /$ day, which is twenty-five times greater than the average intake in the United 
Kingdom in 1700s [2]. A similar trend has been observed in European countries where total sugar consumption contributes to 15 to $25 \%$ of energy supply, with relatively higher intake of added sugars in children compared to adults [3]. In our previous study on a group of patients with stage 2 and 3 chronic kidney disease (CKD), the daily FR intake was $59 \pm 22 \mathrm{~g}$, where added sugars constituted $63 \%$ [4].

Metabolism of FR is distinct from other sugars. It quickly undergoes phosphorylation to fructose-1-phosphate by fructokinase in the liver due to a lack of negative feedback. As a results, the intracellular phosphate $(\mathrm{P})$ and adenosine triphosphate (ATP) depletion can occur transiently with further generation of adenosine monophosphate (AMP), which is then metabolized to inosine monophosphate and eventually to uric acid (UA) [5]. The transient ATP depletion shows some similarities to ischemia and can lead to termination of protein synthesis, oxidative stress and inflammation [6,7]. UA causes reduction in endothelial nitric oxide (NO) level, the key mediator of insulin action, which in turn disturbs blood flow and glucose uptake in skeletal muscles leading to insulin resistance and development of metabolic syndrome (MS) [8].

The clinical and epidemiological evidence also suggests an association between FR consumption and obesity [1], pancreatic beta cell dysfunction [9], type 2 diabetes [1,10], gout, hypertension, chronic kidney disease and cardiovascular disease [11,12]. In developed countries, along with the epidemic of obesity and diabetes, there is also a growing incidence of kidney stone disease in both adults [13] and children [14]. The study by Taylor and Curhan has shown the association between FR consumption from added sugars and kidney stones in three large cohorts of patients. The relative risk of nephrolithiasis was significantly higher in participants with the highest intake of total and free FR compared to those with the lowest intake based on semi-quantitative food frequency questionnaires [15]. It is hypothesized that this association may be caused by increased urinary excretion of calcium (uCaEx) [16], uric acid [17] and oxalate [18], or by the induction of insulin resistance, which is associated with low urine $\mathrm{pH}$ and precipitation of urate salts [19]. A low content of magnesium $(\mathrm{Mg})$ and citrates, which act as crystallization inhibitors, as well as low fibre content in the Western diet, together with processed foods can also promote stone formation in the kidneys and urinary tract $[16,20]$. The prevalence of nephrolithiasis is higher in patients with obesity, metabolic syndrome and type 2 diabetes. At the same time, the risk of calcium oxalate stone formation increases with the number of features of the MS [21].

The role of FR as a causal factor of urolithiasis is still puzzling. On the one hand, epidemiological and clinical studies have shown that FR may be responsible for this disease, while on the other hand consumption of fruits and juices in a diet is still recommended for patients with kidney stones [22]. To our knowledge, the studies conducted so far have not directly confirmed the relationship between the FR diet and the presence of renal calculi. Therefore, we utilized a protocol with diets differing in FR content and its form (liquid vs. solid) to evaluate the kidney tubule function and markers of MS. An experimental model has been utilized to perform a simultaneous histopathological assessment for kidney stones.

\section{Results}

The results are expressed as mean $\pm \mathrm{SD}$ and shown in the following tables.

\subsection{Assessment of Nutritional and Metabolic Status}

The serum FR concentration showed tendency to higher values in rats on F10 and F60 diet compared to RD, with the highest level in F10 group. This may indicate that FR in a liquid form is more easily absorbed from the gastrointestinal tract than in a solid form. The rats showed no difference in total daily calorie intake per day at the end of the experiment, although animals on the F10 and F60 diet consumed significantly less chow than those in the RD group. This was probably due to proportionally more calories consumed in the form of FR. The rats on the F60 diet had significantly lower weight gain, which might be indicative of its toxic potential. There was also a tendency for a lower 
albumin concentration in serum on the fructose-rich diet. Creatinine concentration was lower in F60 as compared to F10 due to a lower body weight of the animals at the end of the experiment. The rats on the F10 and F60 diet, compared to the RD group, showed a trend towards lower values of creatinine clearance. After eight weeks on a fructose-rich diet, the rats presented some features of the metabolic syndrome, namely there was a tendency for higher serum concentration of triglycerides, insulin and high score for the homeostasis model assessment for insulin resistance (HOMA). Interestingly, compared to F60 (solid), the F10 diet (fluid) resulted in a higher insulin concentration in serum. There were no differences with regard to UA levels in serum. The homocysteine (HCS) level significantly increased with the higher FR content in diet. A tendency for higher erythropoietin (EPO) levels was observed in F10 and F60 compared to RD. There were no significant differences in serum concentrations of sodium $(\mathrm{Na})$, potassium $(\mathrm{K})$, magnesium $(\mathrm{Mg})$ and calcium $(\mathrm{Ca})$ despite a tendency for higher phosphate level $(\mathrm{Pi})$ and higher calcium-phosphate product (CaxPi) in fructose-rich diet (Table 1).

Table 1. Nutritional status and serum laboratory data of the animals after 8 weeks period on a regular $\operatorname{diet}(\mathrm{RD})$, a diet supplemented with $10 \%$ of fructose (F10) and $60 \%$ of fructose (F60).

\begin{tabular}{|c|c|c|c|c|c|}
\hline Determined Parameters & RD (I) & F10 (II) & F60 (III) & ANOVA & $\mathbf{P}$ \\
\hline Food consumption [g/day] & $37.9 \pm 2.5$ & $27.2 \pm 4.5$ & $28.6 \pm 2.4$ & $<0.001$ & $\begin{array}{l}\text { I vs. II } \\
\text { I vs. III }\end{array}$ \\
\hline Water consumption [mL/day] & $56 \pm 9$ & $90 \pm 24.5$ & $50 \pm 14$ & $<0.01$ & $\begin{array}{l}\text { I vs. II } \\
\text { II vs. III }\end{array}$ \\
\hline Weight gain [gram] & $275 \pm 23$ & $275 \pm 30$ & $219 \pm 37$ & $<0.01$ & $\begin{array}{l}\text { I vs. III } \\
\text { II vs. III }\end{array}$ \\
\hline Total energy value [kcal per day] & $99.6 \pm 6.6$ & $96.6 \pm 10.3$ & $102.8 \pm 8.9$ & NS & \\
\hline Energy from fructose [kcal/day] & $3 \pm 0.2$ & $27.2 \pm 5.5$ & $61.7 \pm 5.3$ & $<0.001$ & $\begin{array}{l}\text { I vs. II } \\
\text { I vs. III } \\
\text { II vs. III }\end{array}$ \\
\hline Albumin $[\mathrm{g} / \mathrm{dL}]$ & $3.3 \pm 0.1$ & $3.2 \pm 0.2$ & $3.1 \pm 0.2$ & NS & - \\
\hline Fructose $[\mathrm{mg} / \mathrm{dL}]$ & $0.59 \pm 0.05$ & $1.26 \pm 0.7$ & $1.04 \pm 0.5$ & NS & - \\
\hline $\mathrm{BUN}[\mathrm{mg} / \mathrm{dL}]$ & $20.8 \pm 1.4$ & $18.1 \pm 5.2$ & $18.7 \pm 2.6$ & NS & - \\
\hline $\mathrm{HCS}[\mu \mathrm{mol} / \mathrm{L}]$ & $4.5 \pm 0.2$ & $5.8 \pm 1.4$ & $6.4 \pm 1.5$ & $<0.05$ & I vs. III \\
\hline Creatinine $[\mathrm{mg} / \mathrm{dL}]$ & $0.54 \pm 0.04$ & $0.59 \pm 0.09$ & $0.47 \pm 0.04$ & $<0.05$ & II vs. III \\
\hline Creatinine clearance $[\mathrm{mL} / \mathrm{min} / 100 \mathrm{~g}]$ & $0.47 \pm 0.08$ & $0.40 \pm 0.08$ & $0.44 \pm 0.09$ & NS & - \\
\hline Erythropoietin [mIU/mL] & $0.65 \pm 0.56$ & $1.72 \pm 2.01$ & $1.33 \pm 0.84$ & NS & - \\
\hline Uric Acid [mg/dL] & $1.76 \pm 0.4$ & $1.45 \pm 0.3$ & $1.56 \pm 0.1$ & NS & - \\
\hline Insulin [ng/mL] & $3.87 \pm 2.0$ & $5.54 \pm 2.4$ & $5.31 \pm 1.2$ & NS & - \\
\hline HOMA [AU] & $1.94 \pm 0.95$ & $3.13 \pm 1.036$ & $2.36 \pm 0.81$ & NS & - \\
\hline Triglicerides [mg/dL] & $158 \pm 34$ & $180 \pm 27$ & $221 \pm 83$ & NS & - \\
\hline Cholesterol [mg/dL] & $74 \pm 11$ & $60 \pm 9$ & $66 \pm 9$ & NS & - \\
\hline PTH $[\mathrm{pg} / \mathrm{mL}]$ & $225 \pm 112$ & $283 \pm 136$ & $492 \pm 340$ & NS & - \\
\hline Vitamin 25(OH)D3 [ng/mL] & $52 \pm 11$ & $19 \pm 17$ & $31 \pm 44$ & NS & - \\
\hline FGF-23 [pg/mL] & $212 \pm 66$ & $379 \pm 324$ & $216 \pm 51$ & NS & - \\
\hline Calcium [mmol/L] & $2.52 \pm 0.05$ & $2.53 \pm 0.11$ & $2.44 \pm 0.09$ & NS & - \\
\hline Phosphate $[\mathrm{mmol} / \mathrm{L}]$ & $2.32 \pm 0.1$ & $2.39 \pm 0.2$ & $2.60 \pm 0.2$ & NS & - \\
\hline
\end{tabular}


Table 1. Cont.

\begin{tabular}{cccccc}
\hline Determined Parameters & RD (I) & F10 (II) & F60 (III) & ANOVA & P \\
\hline CaxPi $\left[\mathrm{mmol}^{2} / \mathrm{L}^{2}\right]$ & $5.85 \pm 0.36$ & $6.04 \pm 0.49$ & $6.34 \pm 0.59$ & NS & - \\
\hline Magnesium $[\mathrm{mmol} / \mathrm{L}]$ & $2.26 \pm 0.1$ & $2.54 \pm 0.4$ & $2.23 \pm 0.3$ & NS & - \\
\hline Sodium $[\mathrm{mmol} / \mathrm{L}]$ & $140.02 \pm 1.68$ & $139.34 \pm 3.50$ & $140.03 \pm 2.54$ & NS & - \\
\hline Potassium $[\mathrm{mmol} / \mathrm{L}]$ & $5.14 \pm 0.95$ & $5.42 \pm 0.72$ & $5.07 \pm 0.48$ & NS & - \\
\hline
\end{tabular}

BUN—blood urea nitrogen; CaxPi—product of calcium $\times$ phosphate; HCS—homocysteine; HOMA—homeostasis model assessment for insulin resistance; NS-non-statistically significant; PTH—parathyroid hormone; FGF-23—-fibroblast growth factor 23; NS—non-statistically significant.

\subsection{Assessment of Urine}

The rats from the F10 group that were consuming FR as a 10\% water solution, tended to drink more water and produced twice as much urine as rats in the RD and F60 groups. The urine $\mathrm{pH}$ decreased (denoting higher acidity) as the FR content in the diet increased, and it was significantly lower in the F60 group compared to RD and F10 groups. However, the specific gravity increased with the content of FR in the diet and was significantly higher in the F60 group. There were no differences in proteinuria between the groups. Significantly higher urinary excretion of monocyte chemoattractant protein-1 (MCP-1) and N-acetyl-BD-glucosaminidase (NAG) per urinary creatinine was shown with increasing FR content in the diet. Urinary uric acid excretion (uUAEx) decreased with increasing FR content in the diet and was significantly lower in the F10 and F60 groups compared to RD. However, the levels of uric acid clearance (UACl) and fractional uric acid excretion (UAFEx) did not differ between groups. An FR-rich diet resulted in a significantly higher urinary clearance, as well as total excretion and fractional excretion of phosphorus, sodium and calcium. The F60 diet was associated with increased phosphaturia $(>30 \times)$ and natriuria $(4 \times)$ and, to a lesser extent, with increased calciuria. On the other hand, the F10 diet mainly led to increased calciuria $(3 \times)$, and, to a lesser extent, to increased phosphaturia and natriuria. There were no statistical differences in potassium and magnesium excretion with urine between the groups (Table 2).

Table 2. The results of urinalysis and markers of kidney tubular function after 8 weeks period on a regular diet (RD), a diet supplemented with $10 \%$ of fructose (F10) and $60 \%$ of fructose (F60).

\begin{tabular}{|c|c|c|c|c|c|}
\hline Determined Parameters & RD (I) & F10 (II) & F60 (III) & ANOVA & $\mathbf{P}$ \\
\hline Urine output [mL/day] & $26 \pm 9.6$ & $56 \pm 27$ & $25 \pm 13$ & $<0.001$ & $\begin{array}{l}\text { I vs. II } \\
\text { II vs. III }\end{array}$ \\
\hline Urine $\mathrm{pH}$ & $8.5 \pm 0.57$ & $8.2 \pm 0.83$ & $5.6 \pm 0.51$ & $<0.001$ & $\begin{array}{l}\text { I vs. III } \\
\text { II vs. III }\end{array}$ \\
\hline Urine specific gravity $[\mathrm{g} / \mathrm{L}]$ & $1.0125 \pm 0.003$ & $1.014 \pm 0.004$ & $1.026 \pm 0.004$ & $<0.001$ & $\begin{array}{l}\text { I vs. III } \\
\text { II vs. III }\end{array}$ \\
\hline PCR $[\mathrm{mg} / \mathrm{mg} \mathrm{Cr}]$ & $1.0 \pm 0.4$ & $1.1 \pm 0.5$ & $0.8 \pm 0.5$ & NS & - \\
\hline MCP-1/Cr [ng/mg Cr] & $3.5 \pm 0.6$ & $4.4 \pm 4.0$ & $11.2 \pm 2.5$ & $<0.01$ & $\begin{array}{l}\text { I vs. III } \\
\text { II vs. III }\end{array}$ \\
\hline $\mathrm{NAG} / \mathrm{Cr}[\mathrm{U} / \mathrm{g} \mathrm{Cr}]$ & $8.6 \pm 5$ & $15.1 \pm 7.6$ & $20.8 \pm 5$ & $<0.05$ & I vs. III \\
\hline uUAEx [mg/day] & $3.28 \pm 0.51$ & $2.58 \pm 0.57$ & $2.18 \pm 0.66$ & $<0.05$ & I vs. III \\
\hline $\mathrm{UACl}(\mathrm{mL} / \mathrm{min})$ & $0.10 \pm 0.04$ & $0.13 \pm 0.04$ & $0.10 \pm 0.03$ & NS & - \\
\hline UAFEx [\%] & $4.4 \pm 1.2$ & $5.2 \pm 1.6$ & $4.1 \pm 1.6$ & NS & - \\
\hline $\mathrm{uNaEx}[\mathrm{mg} /$ day $]$ & $33.3 \pm 8.5$ & $40.9 \pm 10.8$ & $166.8 \pm 27.2$ & $<0.001$ & $\begin{array}{l}\text { I vs. III } \\
\text { II vs. III }\end{array}$ \\
\hline
\end{tabular}


Table 2. Cont.

\begin{tabular}{|c|c|c|c|c|c|}
\hline Determined Parameters & RD (I) & F10 (II) & F60 (III) & ANOVA & $\mathbf{P}$ \\
\hline $\mathrm{NaCl}[\mathrm{mL} / \mathrm{min}]$ & $0.007 \pm 0.002$ & $0.008 \pm 0.002$ & $0.031 \pm 0.013$ & $<0.001$ & $\begin{array}{l}\text { I vs. III } \\
\text { II vs. III }\end{array}$ \\
\hline NaFEx [\%] & $0.24 \pm 0.08$ & $0.34 \pm 0.06$ & $1.16 \pm 0.45$ & $<0.001$ & $\begin{array}{l}\text { I vs. III } \\
\text { II vs. III }\end{array}$ \\
\hline uPiEx [mg/day] & $1.85 \pm 1.61$ & $4.42 \pm 5.14$ & $75.30 \pm 21.95$ & $<0.001$ & $\begin{array}{l}\text { I vs. III } \\
\text { II vs. III }\end{array}$ \\
\hline $\mathrm{PiCl}[\mathrm{mL} / \mathrm{min}]$ & $0.017 \pm 0.015$ & $0.044 \pm 0.056$ & $0.567 \pm 0.284$ & $<0.001$ & $\begin{array}{l}\text { I vs. III } \\
\text { II vs. III }\end{array}$ \\
\hline PiFEx [\%] & $0.6 \pm 0.6$ & $1.7 \pm 0.2$ & $21 \pm 5$ & $<0.001$ & $\begin{array}{l}\text { I vs. III } \\
\text { II vs. III }\end{array}$ \\
\hline $\mathrm{uCaEx}[\mathrm{mg} /$ day $]$ & $2.02 \pm 0.89$ & $5.71 \pm 3.05$ & $3.08 \pm 1.92$ & $<0.05$ & I vs. II \\
\hline $\mathrm{CaCl}[\mathrm{mL} / \mathrm{min}]$ & $0.014 \pm 0.006$ & $0.038 \pm 0.020$ & $0.019 \pm 0.014$ & $<0.05$ & I vs. II \\
\hline CaFEx [\%] & $0.45 \pm 0.2$ & $1.46 \pm 0.7$ & $0.75 \pm 0.5$ & $<0.05$ & I vs. II \\
\hline $\mathrm{uMgEx}$ [mg/day] & $5.2 \pm 1.9$ & $5.9 \pm 2.1$ & $3.9 \pm 1.4$ & NS & - \\
\hline $\mathrm{MgCl}[\mathrm{mL} / \mathrm{min}]$ & $0.19 \pm 0$ & $0.17 \pm 0.07$ & $0.11 \pm 0.3$ & NS & - \\
\hline MgFEx [\%] & $5.4 \pm 0$ & $6.7 \pm 2.5$ & $4.4 \pm 0.7$ & NS & - \\
\hline uKEx [mg/day] & $174.3 \pm 19.9$ & $152.1 \pm 26.1$ & $124.9 \pm 45.3$ & NS & - \\
\hline $\mathrm{KCl}[\mathrm{mL} / \mathrm{min}]$ & $0.61 \pm 0.1$ & $0.51 \pm 0.1$ & $0.45 \pm 0.17$ & NS & - \\
\hline KFEx [\%] & $19.74 \pm 2.15$ & $19.92 \pm 4.73$ & $16.85 \pm 5.46$ & NS & - \\
\hline & \multicolumn{5}{|c|}{ 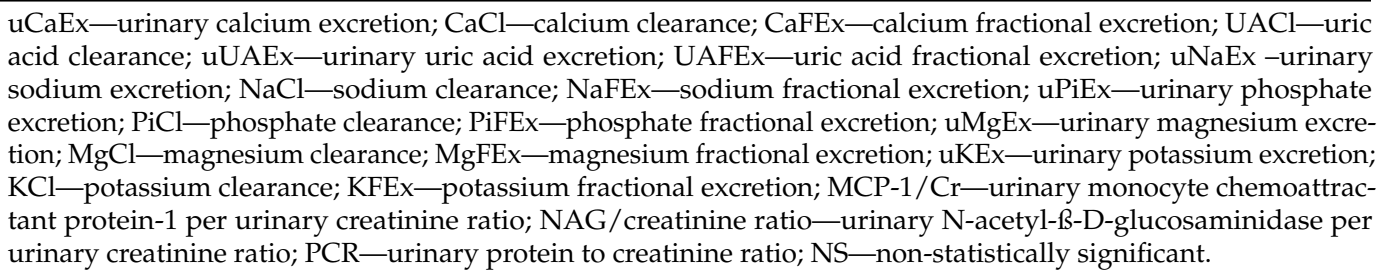 } \\
\hline
\end{tabular}

\subsection{Analysis of Urinary Electrolytes Excretion as a Percentage of Dietary Intake}

Due to the differences in the composition of the F60 diet as compared to the diet used in the RD and F10 groups, a comparative analysis of the amount of sodium, calcium and phosphate provided in each diet was performed. Dietary sodium intake from diet was $20 \%$ lower in F10 and 20\% higher in F60 compared to the RD. Calcium and phosphate intake from diet was lower for both electrolytes by 30\% in F10 than RD. In the same time, it was reducing by $60 \%$ for calcium and 30\% for phosphate in F60 as compared to RD. The ratio of urinary electrolytes (sodium, calcium, phosphate) excretion as a percentage of dietary intake was also calculated (Table 3).

Table 3. The mean daily amount of Sodium, Calcium and Phosphate provided in RD, F10 and F60 diet and the ratio of daily urinary Excretion of Sodium, Calcium and Phosphate as percentage of their daily dietary intake from diet.

\begin{tabular}{cccccc}
\hline Determined Parameters & RD (I) & F10 (II) & F60 (III) & ANOVA & P \\
\hline Sodium intake from diet [mg/day] & $113.7 \pm 7.6$ & $81.6 \pm 13.6$ & $142.0 \pm 12.4$ & $<0.001$ & I vs. II \\
& & & & I vs. III \\
II vs. III & I vs. II \\
uNaEx/Na consumed in diet [\%] & $29.2 \pm 6.8$ & $50.7 \pm 12.7$ & $117.0 \pm 10.4$ & $<0.001 \quad$ I vs. III \\
\end{tabular}


Table 3. Cont.

\begin{tabular}{|c|c|c|c|c|c|}
\hline Determined Parameters & RD (I) & F10 (II) & F60 (III) & ANOVA & $\mathbf{P}$ \\
\hline Calcium intake from diet [mg/day] & $417 \pm 28$ & $299 \pm 50$ & $174 \pm 15$ & $<0.001$ & $\begin{array}{l}\text { I vs. II } \\
\text { I vs. III } \\
\text { II vs. III }\end{array}$ \\
\hline $\mathrm{uCaEx} / \mathrm{Ca}$ consumed in $\operatorname{diet}[\%]$ & $0.5 \pm 0.2$ & $1.9 \pm 0.9$ & $1.8 \pm 1.1$ & $<0.05$ & $\begin{array}{l}\text { I vs. II } \\
\text { I vs. III }\end{array}$ \\
\hline Phosphate intake from diet [mg/day] & $227 \pm 15$ & $163 \pm 27$ & $156 \pm 14$ & $<0.001$ & $\begin{array}{l}\text { I vs. II } \\
\text { I vs. III }\end{array}$ \\
\hline uPiEx/Pi consumed in diet [\%] & $0.8 \pm 0.7$ & $3.0 \pm 3.6$ & $47.7 \pm 11.1$ & $<0.001$ & $\begin{array}{l}\text { I vs. III } \\
\text { II vs. III }\end{array}$ \\
\hline
\end{tabular}

$\mathrm{Ca}$-calcium; $\mathrm{Na}$-sodium; $\mathrm{Pi}$-phosphate; $\mathrm{uCaEx}$ - urianry calcium excretion; $\mathrm{uNaEx}$ - urinary sodium excretion uPiEx-urinary phosphate excretion.

\subsection{Kidney Histopathology}

The microscopic examination of kidney specimens revealed a focal interstitial and tubular basophilic deposits (calcium phosphate stones) in two animals from the F10 group and another two animals from the F60 group. The stones were located in the cortex and renal medulla, in all parts of the nephron. In haematoxylin and eosin (HE) stained tissue sections the concretions were non polarizable, small, round and exhibiting psammoma body-like substructure with concentric rings (Figures 1-4). Von Kossa staining revealed brown-black calcifications. Additionally, the light microscopy revealed focal and mild tubulo-interstitial lymphocytic infiltration in rats from F10 and F60 groups (Figures 5 and 6). There were no morphological features of acute tubular injury, inflammation nor calcium depositis in kidney of rats from RD group (Figure 7).

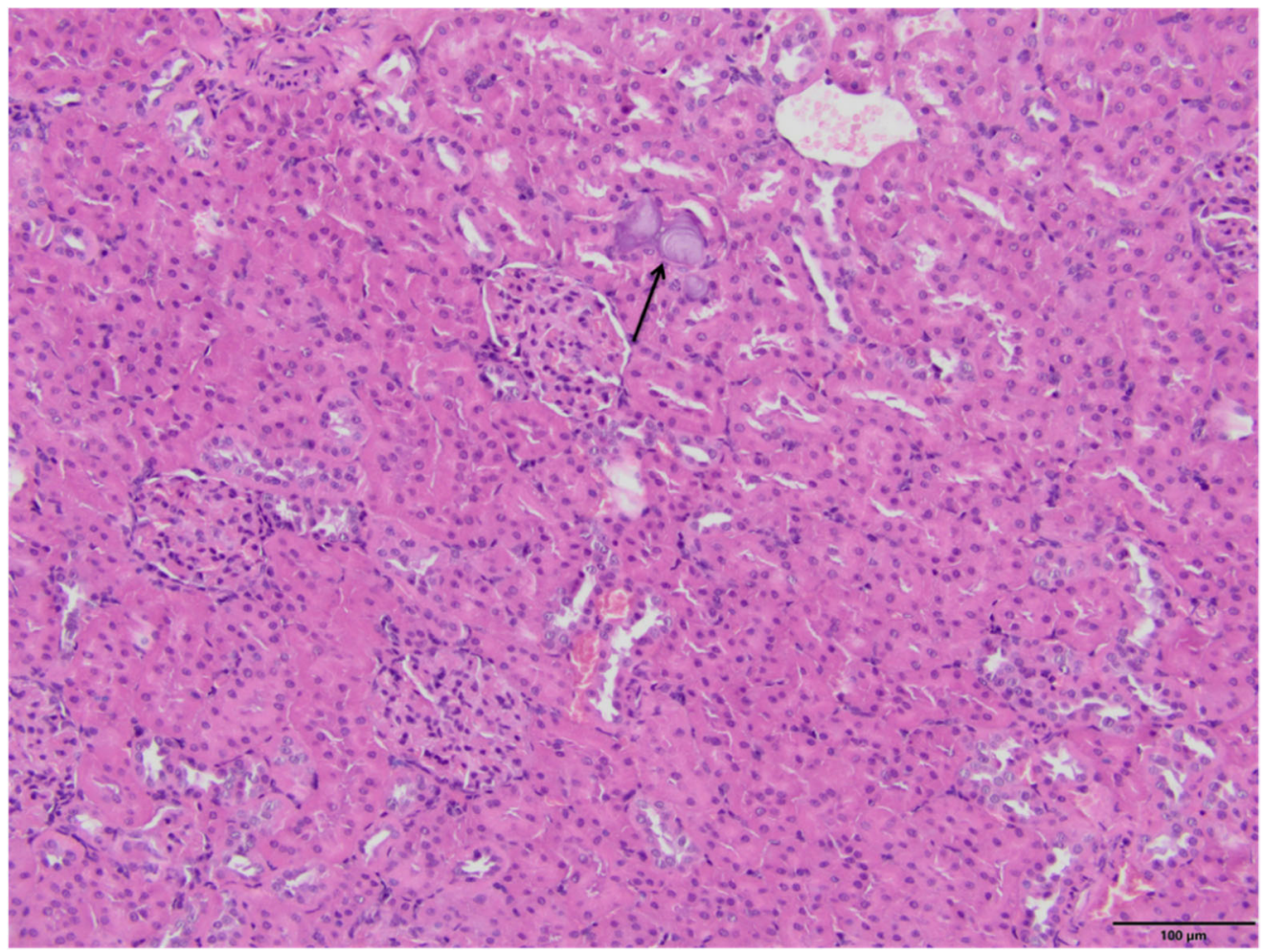

Figure 1. Pathological lesions in kidneys of rats on $10 \%$ fructose diet (F10). The purple concretions within the interstitium and tubules with ring-like substructures (arrow). The deposits are non-polarizable, displacing the proximal tubule epithelium and narrowing the lumen. (HE, magnification $20 \times$ ). 


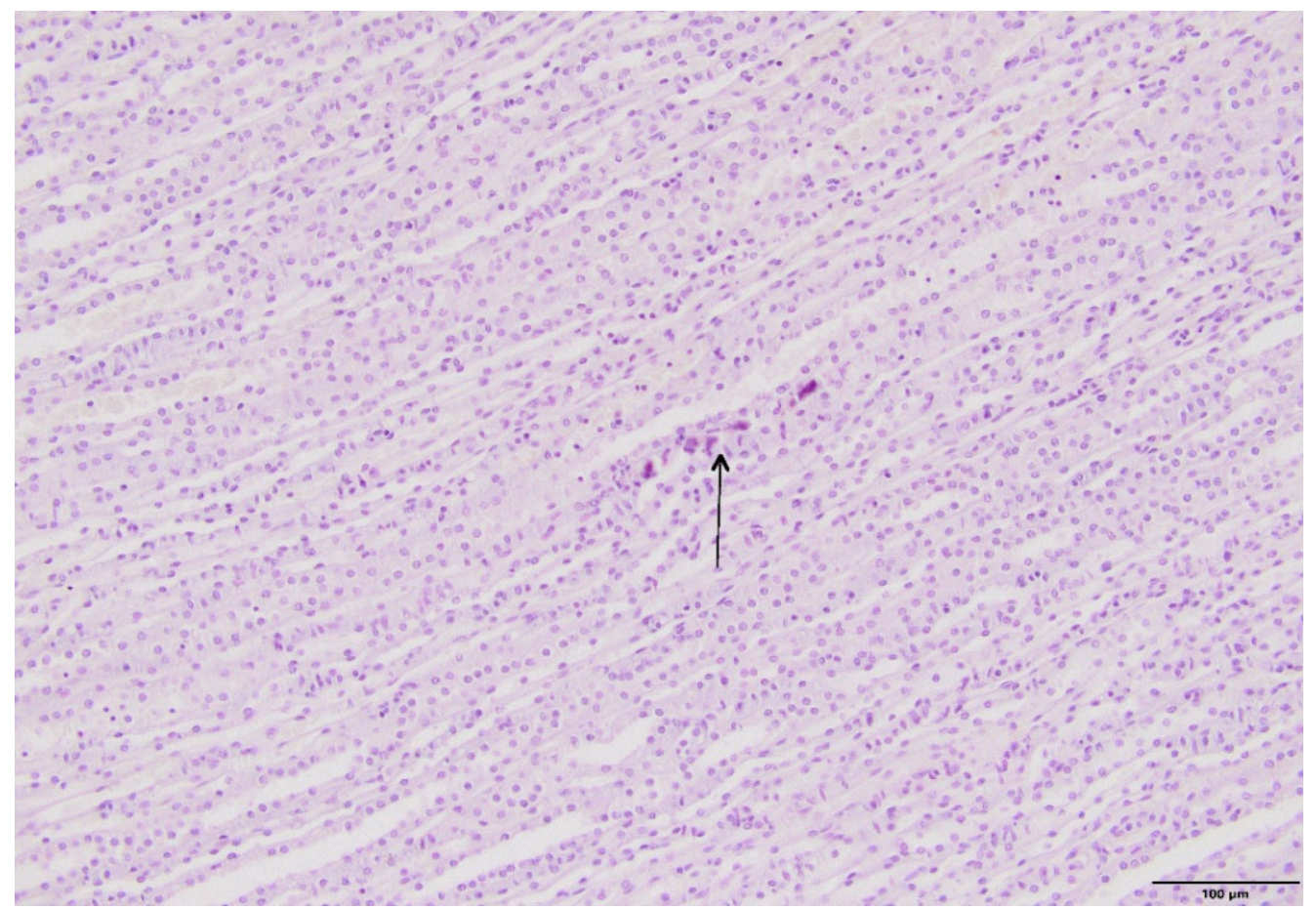

Figure 2. Pathological lesions in kidneys of rats on $10 \%$ fructose diet (F10). Basophilic deposits in area of renal medulla (arrow) (HE, magnification $20 \times$ ).

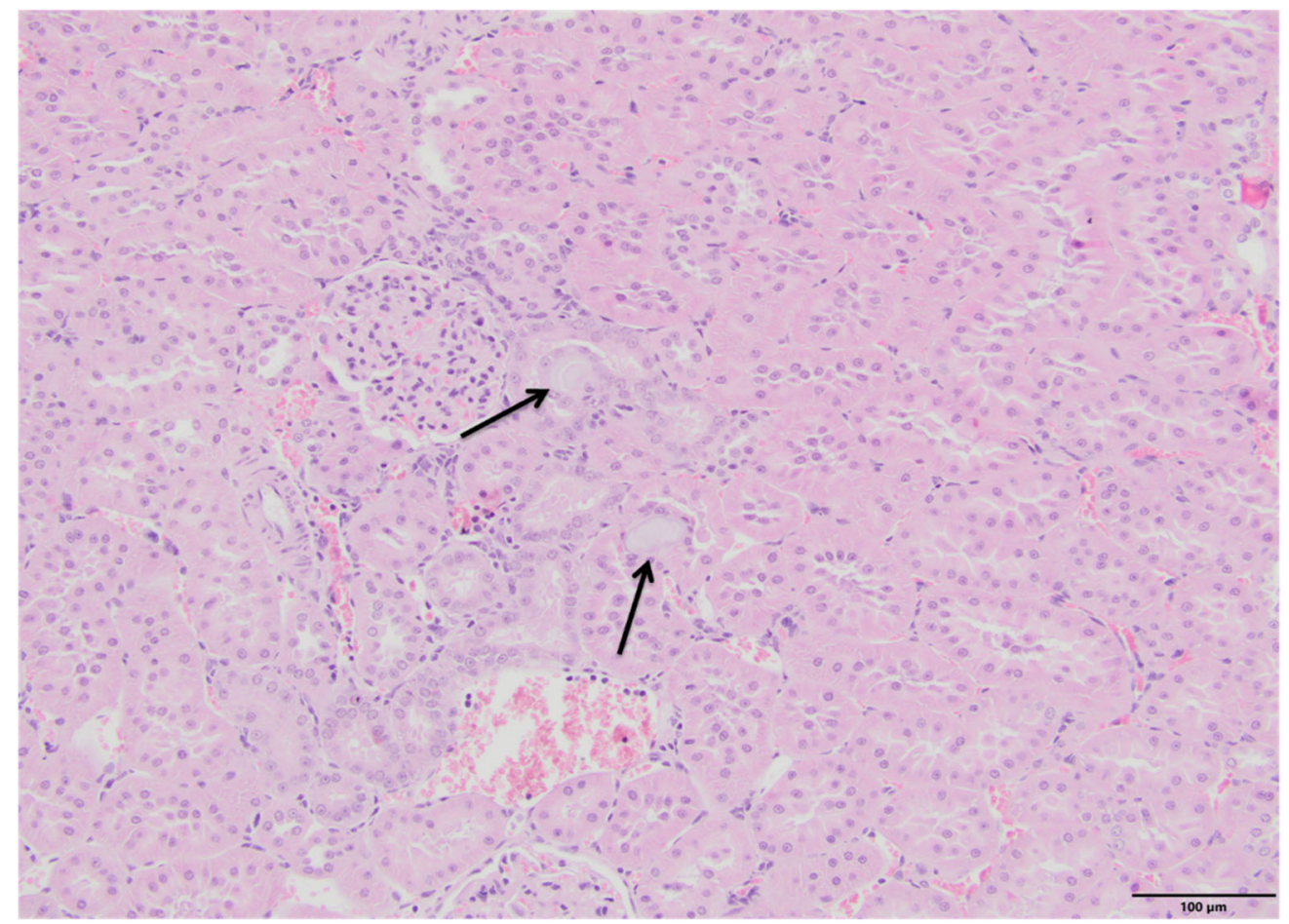

Figure 3. Pathological lesions in kidneys of rats on 60\% fructose diet (F10). Two pale basophilic deposits with delicate ring-like substructure within interstitium (arrows). The deposits are nonpolarizable, compressed the tubular structures. (HE, magnification $20 \times$ ). 


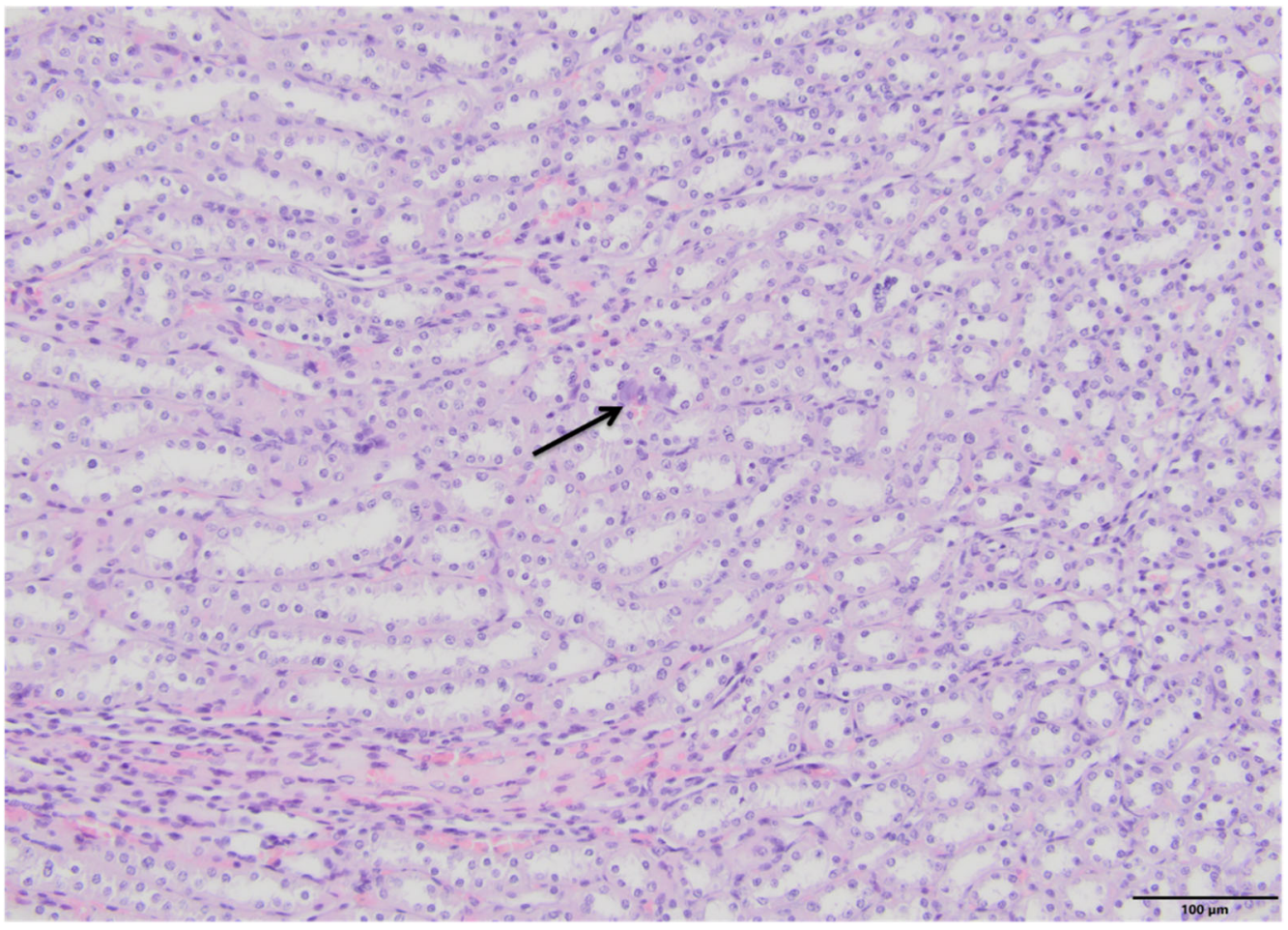

Figure 4. Pathological lesions in kidneys of rats on $60 \%$ fructose diet (F60). Two small basophilic interstitial and tubule-associated concretions in renal medulla (arrow). (HE, magnification 20×).

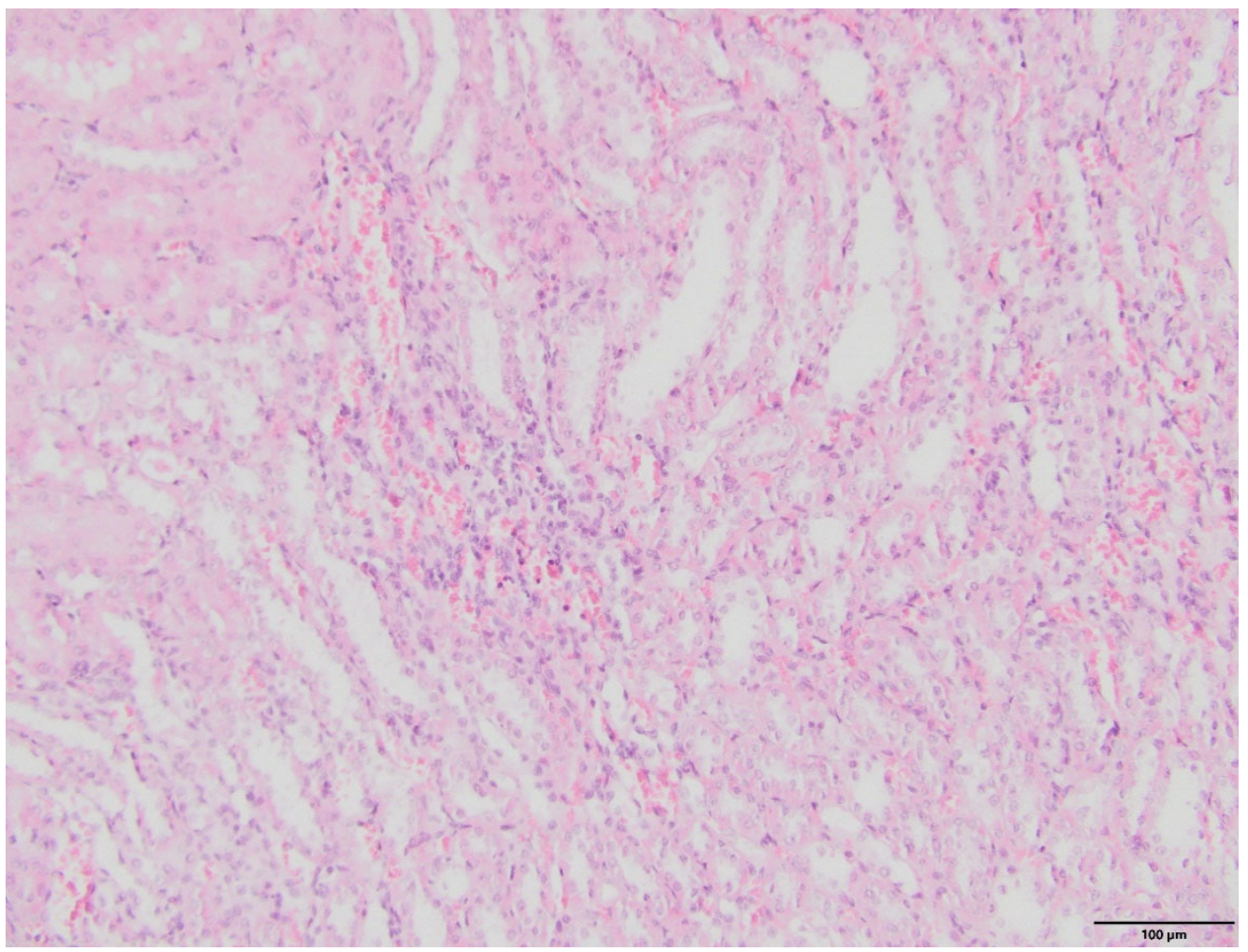

Figure 5. Pathological lesions in kidneys of rats on 10\% fructose diet (F10). Mild tubule-interstitial mononuclear cell infiltration. (HE, magnification $20 \times$ ). 


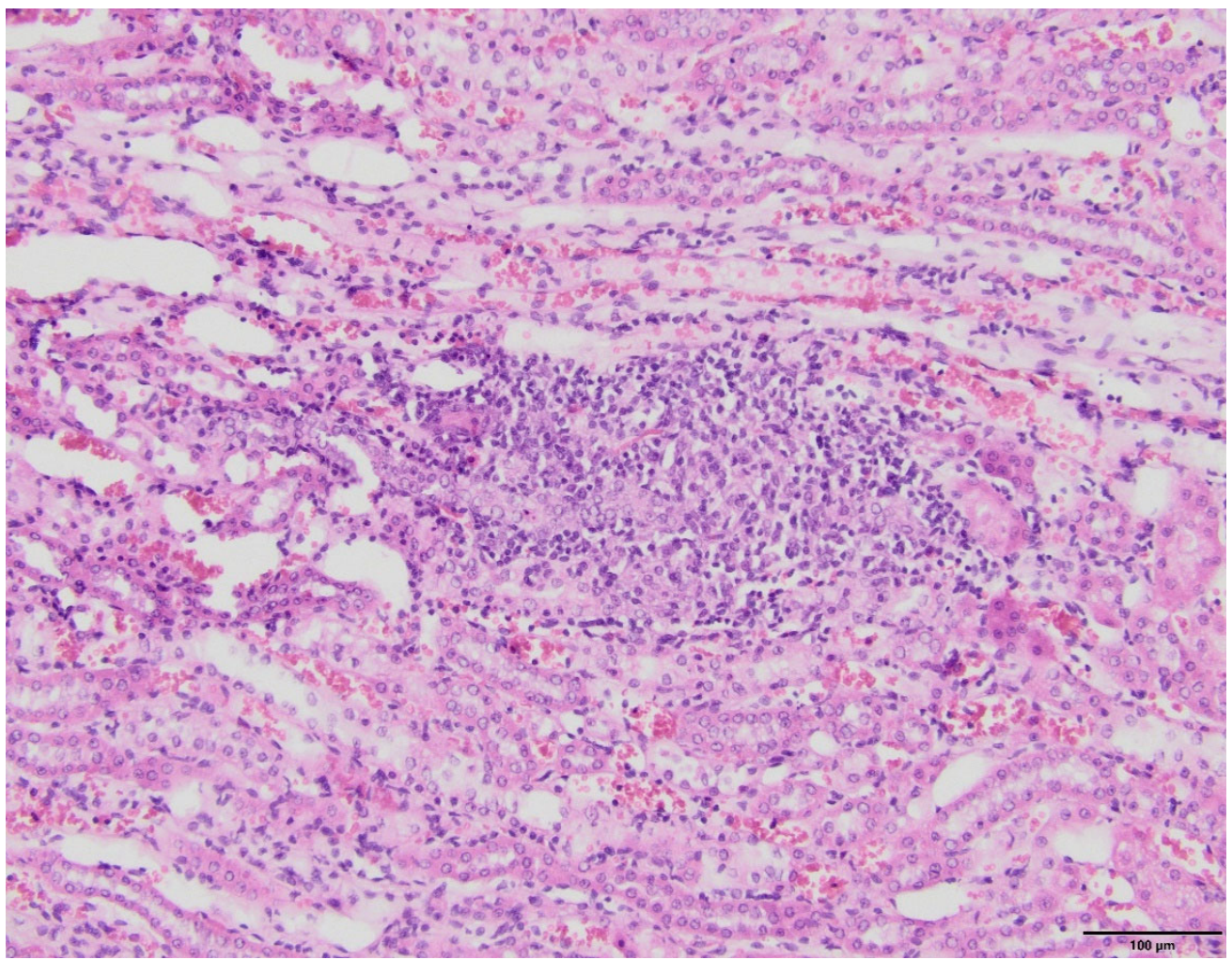

Figure 6. Pathological lesions in kidneys of rats on $60 \%$ FR diet (F60). Moderate lymphocytic infiltration of renal tubules and interstitium. (HE, magnification $20 \times$ ).

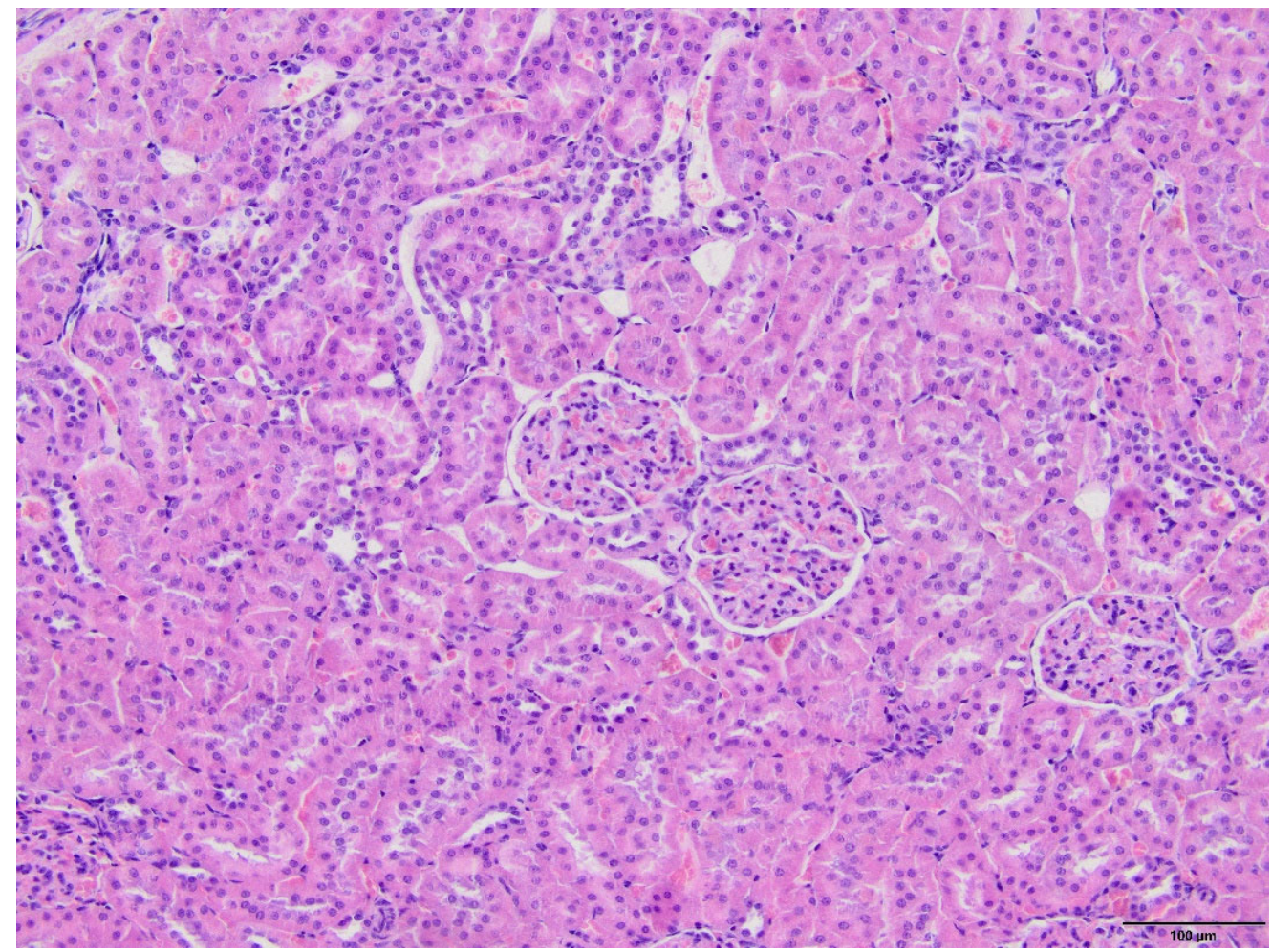

Figure 7. Kidney of rat on regular diet (RD). All structural elements of the kidney are seen: three glomeruli without structural abnormalities, normal tubules, interstitium and blood vessels. (HE, magnification $20 \times$ ). 


\section{Discussion}

Our study confirmed that FR intake led to the development of some features of MS as an increased serum insulin, HOMA and triglyceride level. FR also induced local inflammatory response, mediated by MCP-1, leading to the renal proximal tubular injury, indicated by increased urinary excretion of NAG and the presence of mononuclear cells infiltration in kidney parenchyma (Figures 5 and 6). Interestingly, our study also confirmed that FR given in the form of fluid (F10) as compared to a solid feed (F60) resulted in a higher insulin concentration in serum. This was probably due to the fact that F10 was more eagerly consumed by animals than F60 (Table 1). In our previous study conducted on the same group of rats, we showed that F10 versus F60 stimulated higher secretion of insulin and C-peptide by the pancreatic islet cells, and lead to more pronounced insulin resistance [9]. Moreover, our study showed that FR given as a 10\% liquid solution significantly increased $\mathrm{uCaEx}$ and reduced uUAEx, while in the form of a solid $60 \%$ feed, it further decreased the uUAEx, led to urine acidification and induced severe uPiEx (Table 2).

An important observation of this study was a microscopic confirmation of precipitated calcium deposits in the renal tubules and kidney parenchyma only in rats on high-fructose diet, respectively, in two rats from F10 (Figures 1 and 2) and another two in F60 groups (Figures 3 and 4). Based on histopathological analysis (HE and von Kossa staining) we assumed that those concretions can be made of calcium phosphate (Figures 1-4). A stone forming rats from F10 and F60 groups were characterized by a significantly higher concentration of serum insulin, increased $\mathrm{CaCl}$, as well as increased $\mathrm{uCaEx}, \mathrm{CaFEx}$, and, interestingly, increased $\mathrm{uMgEx}$ (Table 4). Interestingly, due to the fact that F10 rats, compared to F60 rats, excreted twice as much urine of low specific gravity, our results suggest that despite hypersaturation of urine, there are also other specific metabolic disturbances induced by FR responsible for lithogenesis.

Table 4. Metabolic characteristics of rats on fructose-rich diet (F10 + F60) developing stones versus animals without kidney stones.

\begin{tabular}{cccc}
\hline Metabolic Characteristics & Rats without Kidney Deposits $(\mathbf{N}=7)$ & Rats with Kidney Deposits (N = 4) & ANOVA \\
\hline Insulin $[\mathrm{ng} / \mathrm{mL}]$ & $4.60 \pm 1.60$ & $6.86 \pm 0.83$ & $<0.05$ \\
\hline $\mathrm{uCaEx}[\mathrm{mg} / \mathrm{day}]$ & $2.02 \pm 0.89$ & $5.71 \pm 3.05$ & $<0.01$ \\
\hline $\mathrm{CaCl}[\mathrm{mL} / \mathrm{min}]$ & $0.018 \pm 0.011$ & $0.047 \pm 0.015$ & $<0.01$ \\
\hline $\mathrm{CaFEx}[\%]$ & $0.73 \pm 0.42$ & $1.67 \pm 0.58$ & $<0.05$ \\
\hline $\mathrm{uMgEx}[\mathrm{mg} /$ day] & $3.93 \pm 1.22$ & $6.39 \pm 2.16$ & $<0.05$ \\
\hline
\end{tabular}

$\mathrm{CaCl}$-calcium clearance; uCaEx-urinary calcium excretion; CaFEx-calcium fractional excretion $\mathrm{uMgEx}$ - urinary magnesium excretion.

The commonly crystallizing calcium salts in the kidney are calcium phosphate (CaPi) and calcium oxalate (CaOx) [22], the latter can form on the basis of UA crystals [19]. It is thought that high urine $\mathrm{pH}$ favours calcium phosphate (CaPi) crystallization, while low or neutral $\mathrm{pH}$ promoted precipitation of calcium oxalate (CaOx) [23]. Studies on animal model indicate that intratubular nephrocalcinosis is a result of urinary supersaturation with a variety of compounds including $\mathrm{CaPi}, \mathrm{CaOx}$ and $\mathrm{UA}$, while interstitial nephrocalcinosis is associated with inflammation and the deposition of poorly crystallized CaPi [24]. Furthermore, $\mathrm{CaPi}$ crystals can precipitate in renal tubules and form extends outward through kidney interstitium to the renal papilla where promote crystallization of $\mathrm{CaOx}$ stones [23].

\subsection{Fructose Induced Metabolic Syndrome and Inflammation}

It has been confirmed in a rat model that a fructose-enriched diet given for 5 weeks may induce a complete MS, including hypertension, hyperinsulinemia, hypertriglyceridemia and hyperhomocysteinemia [25]. HCS stimulates MCP-1 expression in the renal proxi- 
mal tubular cells by activation of nuclear factor-kappa B (NF- $\mathrm{kB})$ and may contribute to progression of chronic kidney disease [26].

We found that serum concentration of HCS and urinary excretion of MCP-1 and NAG increased with FR content in diet, reaching a statistical significance for the F60 group compared to the RD group (Table 2). While the impact of an FR-rich diet on inflammatory markers and proximal tubular injury was proportional to the FR content in diet, it is suggested that the toxic effect might depend on the FR concentration in the tubular fluid. It has also been confirmed that FR increases intracellular levels of UA in the proximal tubular cells, which further induces an inflammatory response [27]. Similarly, in the study conducted on rats receiving $250 \mathrm{~g} / \mathrm{L}$ of FR in the form of a fluid solution for 16 months versus glucose and sucrose diet, it has been established that the inflammatory injury of the renal tubules and glomeruli are proportional to the FR concentration in urine [28]. Additionally, ingestion of $10 \%$ FR for eight weeks has induced renal microvascular disease and glomerular hypertension in rats [12], while the diet containing $60 \%$ of FR versus normal or dextrose diet caused tubule-interstitial injury and interstitial macrophage infiltration in rats $[29,30]$.

In fact, we found a tendency for higher concentration of EPO in the F10 and F60 groups compared to the RD group, which might be a hallmark of tubule-interstitial injury secondary to inflammation or ischemia [31]. Meanwhile, the microscopic examination confirmed that both F10 and F60 rats showed the presence of focal lymphocytic infiltrates within the tubulointerstitial compartment (Figures 5 and 6). However, an FR diet for an 8-week period was not sufficient to produce a significant change in creatinine clearance $(\mathrm{CrCl})$ between F10, F60 and RD groups (Table 1). Undoubtedly, extending the duration of fructose-rich diet period would have led to a more significant kidney injury.

Insulin resistance acts at the kidney level by reducing urinary $\mathrm{pH}$, thus hampering the ability of the kidney to generate renal ammonium in response to an acid load [32]. Furthermore, insulin resistance is characterized by increased excretion of titratable acids (e.g., phosphates and sulphates) and low urinary concentration of citrate [19]. The other authors have also reported lower uUAEx in fructose-fed rats $[31,33]$. This phenomenon in rats fed on a 10\% FR diet can rely on an abnormal expressions of urate transporters in the proximal tubule secondary to hyperinsulinemia, dyslipidaemia and inflammation [33]. Furthermore, a fructose-rich diet given for three months does not lead to significant differences in serum UA concentration, and eventually prolongation of the diet up to 5 months has resulted in a significant hyperuricemia [17]. It is also thought that FR does not increase uric acid level significantly in rats due to the presence of the uricase which causes degradation of uric acid [10]. Similarly to previously mentioned studies, the significantly lower uUAEx was present in both F10 and F60 groups as compared to the RD group, despite the fact that there was no significant differences in concentration of UA in serum, nor $\mathrm{UACl}$ and UAFEx (Tables 1 and 2). Moreover, patients with MS are also characterized by increased uCaEx and the risk of calcium stone formation in such patients is proportional to the number of features of the MS [21]. Those factors may predispose to uric acid and calcium stones formation, as both low urine $\mathrm{pH}$ and low urine volume are known risk factors of UA precipitation [32].

\subsection{Fructose Effects on Macro-Mineral Homeostasis}

Our study confirmed that an FR diet negatively affects macro-mineral homeostasis leading to significantly higher $\mathrm{uCaEx}$, as well as uPiEx and $\mathrm{uNaEx}$ in relation to their dietary intake (Table 3). The same observation has also been shown in humans [34]. Although we did not find a significant difference in serum calcium (Ca) level, a significantly higher $\mathrm{uCaEx}$ was present in the F10 group compared to the RD and F60 groups. However, in the F60 group, uCaEx was two times smaller as compared to the F10 group and was only insignificantly higher compared to the RD group (Table 2). This fact was not related to the diet, since the content of Ca consumed by rats was significantly lower in groups F10 and 
F60 compared to the RD group. At the same time, the ratio of uCaEx per Ca consumed from the diet was significantly higher in groups F10 and F60 than in RD group (Table 3).

$\mathrm{Up}$ to $60 \%$ of filtered $\mathrm{Ca}$ is reabsorbed in the proximal tubule due to the sodiumhydrogen exchanger 3 (NHE3), which is responsible for trans-epithelial sodium flux and consequently provides the osmotic driving force for water flux and the driving force for passive para-cellular Ca flux [35]. NHE3 is also known to be regulated by the calciotropic hormones, i.e., PTH [36] and 1,25-dihydroxy vitamin $\mathrm{D}_{3}$ [37]. It has been confirmed that an increase of $\mathrm{uCaEx}$ is characteristic for all sugars including glucose and sucrose [38].

An FR diet, as compared to glucose, can increase Ca content in the rat kidney homogenates up to eight times, but only when the diet is lacking in magnesium [16]. We did not find significant differences in serum $\mathrm{Mg}$ or $\mathrm{uMgEx}$ in a baseline characteristics of the groups (Tables 1 and 2). Although, the stone-forming rats on the FR diet were characterized by significantly higher uMgEx than rats on the FR diet without deposits in kidney on microscopy (Table 4). Mg is generally known to inhibit lithogenesis as it can bind to oxalate [39] and it competes with Ca ions to make a complex with oxalate, which is more soluble than $\mathrm{CaOx}$ [40]. There have also been reports discrediting any beneficial effects of $\mathrm{Mg}$ therapy for nephrolithiasis [41]. On the other hand, the Mg-deficient rats on FR diet have developed nephrocalcinosis caused by deposition of $\mathrm{CaPi}$ rather than $\mathrm{CaOx}$ [16]. Therefore, the effect of $\mathrm{Mg}$ on the development of $\mathrm{CaPi}$ kidney stones may be limited. Due to technical problems, we did not measure oxalate excretion in urine and thus its role in the formation of calcium deposits in this experiment could not be ruled out.

At the same time, the uPiEx and $\mathrm{uNaEx}$ increased along with the FR content in diet in our study. The uPiEx was two times greater in the F10 group and more than thirty times higher in the F60 group compared to the RD group (Table 2). However, only a tendency to higher serum Pi concentration in the F60 group was observed as compared to the F10 and RD groups (Table 1). The rats in F10 and F60 groups consumed about $30 \%$ less of Pi from diet compared to the RD group. Despite this fact, the ratio of uPiEx to Pi consumed from diet was severely elevated, especially in F60 rats (Table 3). The other studies have also confirmed that dietary FR, as compared to glucose [42] and starch [35], results in greater $\mathrm{uPiEx}$ in rats [42]. Moreover, a study on rats fed $63 \%$ FR confirms a significant decrease in $\mathrm{Ca}$ and Pi content in the femur and tibia [43]. Thus, FR-rich diet has also led to a negative Pi balance secondary to increased serum alkaline phosphatase activity and higher uPiEx [35]. Research showed that $60-70 \%$ of the filtered $\mathrm{Pi}$ is reabsorbed in the proximal tubule [44]. Pi reabsorption is achieved mainly by controlling the apical expression of a few types of sodium-phosphate cotransporters $(\mathrm{NaPi})$ localized in renal proximal tubules and are regulated by $\mathrm{PTH}$, vitamin $\mathrm{D}$ and dietary $\mathrm{Pi}$ [37].

In order to understand the mechanism of increased calcium and phosphorus excretion the concentration of PTH, FGF-23 and 25(OH)-vitamin D3 (D3) was measured. There were no statistically significant differences in the analyzed parameters between the groups. Although, there was a trend towards a higher concentration of PTH and a lower level of D3 in F10 and F60 groups compared to the RD group (Table 1). Therefore, the results of our experiment may indicate renal tubular damage associated with a high-fructose diet.

Interestingly, a study exploring the effect of ingestion of $200 \mathrm{~g}$ of FR daily for two weeks by healthy men has also confirmed an increase in PTH concentration and a decrease in serum ionized calcium [45]. meanwhile, another study conducted on rats fed with FR for four weeks indicated a decrease in circulating levels of 1,25-(OH)2D3 due to diminished activity of $1 \alpha$-hydroxylase with secondary inhibition of calcium reabsorption in the intestines and kidneys. Interestingly, those animals also developed osteoporosis [46].

Fructose-induced tubulointerstitial injury may be connected with secondary deficiency of active vitamin D3 and disturbances in PTH production. Those abnormalities eventually might be responsible for the progression of CKD and have a detrimental effect on bones. Thus, fructose emerges as a culprit responsible not only for today's epidemic of cardiovascular diseases but also for nephrolithiasis and osteoporosis. 
Finally, we would like to mention some limitations of the current study. The composition of the diet in the F60 group was different, apart from the fructose, in respect to protein, fat, vitamin D, and mineral content compared to F10 and RD groups. The choice of this feed was determined by the fact that it was the only commercially available diet with $60 \%$ fructose content. Since the composition of the F60 diet could affect the results of urinary excretion of calcium and phosphate, the amount of food and minerals consumed by the animals was analyzed during the experiment. An evaluation of urinary excretion of oxalate and citrate should be performed, as data from the literature suggest that the FR diet and metabolic syndrome may be associated with increased oxalate excretion in urine and decreased urinary citrate excretion. The present study was conducted on a small groups of male rats. Due to the fact that sex hormones may influence the urine composition, the effect of FR-diet should also be confirmed in female rats. It would also be appropriate to use a technique which does not rinse out any uric acid crystals during tissue preparation for histopathology evaluation. Application of X-ray diffraction analysis technique for precise characterization of the intraluminal and interstitial deposits would have added highly valuable information to this study.

Despite those shortcomings, we believe that the preliminary results of this study provide valuable information as they confirm, for the first time, the direct relationship between the high-FR diet and the presence of precipitated calcium deposits in the renal tubules and kidney parenchyma confirmed by microscopy examination.

\section{Materials and Methods}

\subsection{Animal Model}

All animal procedures were performed in compliance with the National Institutes of Health Guide for the Care and Use of Laboratory Animals and approved by the Institutional Committee for Animal Welfare at Bydgoszcz (no. 13/2007 and 22/2011), in accordance with the Polish Act on Experiments on Animals (Journal of Laws 2005/33/289) and the Directive of the European Parliament No. 2003/65/EC. Male Wistar rats were purchased from Mossakowski Medical Research Centre, the Polish Academy of Sciences, Warsaw, Poland. The animals had the initial body mass of $386 \pm 40 \mathrm{~g}$ and were at the age of eight weeks at the beginning of the experiment. They were randomly assigned to three groups and kept for eight weeks on the following diets: $\mathrm{RD}(n=5)$ regular diet with FR concentration $<3 \%$, given in the form of pelleted chow (Agropol, Poland); F10 $(n=6)$ consisting of regular diet supplemented with $10 \%$ solution of FR in drinking water (Biofan Fruktoza, Poland); and F60 $(n=5)$ consisting of 60\% FR in diet in the form of pelleted chow (TD.89247, Harlan Tekland, Cambridge, WI, USA). The RD diet contained 16\% protein, $2.8 \%$ fat, $1.10 \%$ calcium, $0.7 \%$ phosphorus, $0.22 \%$ sodium, and $800 \mathrm{IU} / \mathrm{kg}$ of vitamin D3. The F60 diet contained $18.3 \%$ protein, $5.2 \%$ fat, $0.6 \%$ calcium, $0.54 \%$ phosphorus, $0.49 \%$ sodium, $500 \mathrm{IU} / \mathrm{kg}$ of vitamin D3. The animals were maintained under a constant $12 \mathrm{~h}$ photoperiod in a temperature between $21^{\circ} \mathrm{C}$ and $23^{\circ} \mathrm{C}$. They were allowed free access to water and chow. The daily energy intake was calculated. The body mass was measured at the beginning and at the end of the experiment. Furthermore, at the end of the study, $24 \mathrm{~h}$ urine collections were conducted and samples were collected using individualized metabolic cages. The rats were then sacrificed and blood samples were collected from the right ventricle of the heart for biochemical analysis following a $4 \mathrm{~h}$ period of fasting. The urine and serum were collected and stored at $-80^{\circ} \mathrm{C}$ before further analysis.

\subsection{Laboratory Tests}

Serum BUN, creatinine ( $\mathrm{Cr}$ ), albumin, glucose, triglycerides, uric acid (UA), sodium $(\mathrm{Na})$, potassium $(\mathrm{K})$, calcium $(\mathrm{Ca})$, phosphates $(\mathrm{Pi})$ and magnesium $(\mathrm{Mg})$ were measured using Architect ci8200 (Abbott Laboratories, Wiesbaden, Germany) according to the manufacturer's operating protocol. Serum fructose (FR) concentration was determined based on the quantitative colorimetric method (BioAssay Systems, Hayward, CA 94545, USA). Serum insulin was tested using the ELISA assay (Alpco Immunoassays, Salem, NH 03079, 
USA). The homeostasis model assessment for insulin resistance (HOMA-IR) was calculated using the following equation: [fasting plasma insulin $(\mathrm{ng} / \mathrm{mL}) \times$ fasting plasma glucose $(\mathrm{mg} / \mathrm{dL}) / 405]$. EPO was determined using the ELISA assay (Roche Diagnostics GmbH, Mannheim, Germany).

Serum homocysteine was determined by the fluorescence polarization immunoassay using AxSYM (Abbott Laboratories, Wiesbaden, Germany). Quantitative determination of parathyroid hormone (PTH) and fibroblast growth factor 23 (FGF-23) level in plasma was done by ELISA assays (Immutopics International, San Clemente, CA 92673, USA). Serum concentration of 25(OH) Vitamin $\mathrm{D}_{3}$ was tested using the Elisa Kit (Abcam, Cambridge, MA, USA). The analysis of a $24 \mathrm{~h}$ urine collection included measurement of the volume, urine $\mathrm{pH}$, specific gravity, as well as daily excretion of protein, monocyte chemoattractant protein-1 (MCP-1), and N-acetyl- $\beta$-D-glucosaminidase (NAG). Urine $\mathrm{Cr}, \mathrm{UA}, \mathrm{P}, \mathrm{Ca}, \mathrm{Mg}, \mathrm{Na}$ and $\mathrm{K}$ were measured using Architect ci8200 (Abbott Laboratories, Wiesbaden, Germany). The urine specific gravity and $\mathrm{pH}$ were determined by urine dipstick test (Combur-10 Test; Urisys 1100; Cobas, Roche Diagnostics GmbH, Mannheim, Germany). MCP-1 in urine was tested with the ELISA assay (IBL America, Minneapolis, MN 55432, USA), while NAG in urine was tested by colorimetry (Roche Diagnostics $\mathrm{GmbH}$, Mannheim, Germany). Renal clearances $(\mathrm{Cl})$ as well as fractional excretions (FEx) of $\mathrm{Cr}, \mathrm{UA}, \mathrm{P}, \mathrm{Ca}, \mathrm{Mg}$, Na and K were calculated using the following formulas:

$$
\begin{array}{r}
\mathrm{Cl}_{(\mathrm{x})}(\mathrm{mL} / \mathrm{min})=\left[\mathrm{U}_{(\mathrm{x})}(\mathrm{mg} / \mathrm{dL}) \times \text { urine volume }(\mathrm{mL} / 24 \mathrm{~h})\right] /\left[\mathrm{S}_{(\mathrm{x})}(\mathrm{mg} / \mathrm{dL}) \times 1440(\mathrm{~min})\right] . \\
\operatorname{FEx}_{(\mathrm{x})}=\left(\mathrm{U}_{(\mathrm{x})} \times \mathrm{S}_{\mathrm{Cr}} / \mathrm{U}_{\mathrm{Cr}} \times \mathrm{S}_{(\mathrm{x})}\right) \times 100
\end{array}
$$

where $\mathrm{U}$ is the concentration of the analyzed substance $(x)$ in urine and $\mathrm{S}$ is the concentration of the analyzed substance in serum.

\subsection{Histology}

The kidneys were removed, decapsulated, placed in 10\% buffered formalin and prepared for light microscopy (LM). The $5 \mu \mathrm{m}$ thick paraffin-embedded sections were stained with hematoxylin and eosin as well as von Kossa stain, and later studied using bright field and polarized microscopy. The specimens were assessed for presence of pathological lesions, especially in the tubulointerstitial compartment, as well as for crystal distribution within the kidneys. Oxalate crystals are typically translucent, whereas calcium phosphate crystals often appear blue or purple on H\&E staining. The von Kossa stain reacts with the phosphate anion of calcium phosphate and, therefore, does not stain calcium oxalate [47].

\subsection{Statistical Analysis}

Statistical analysis was conducted using the one-way analysis of variance with Bonferoni post-hoc test. The differences were considered statistically significant for $p<0.05$.

\section{Conclusions}

In summary, we showed that dietary fructose consumption is associated with induction of the metabolic syndrome phenotype and local inflammatory response (MCP-1) in the proximal tubules. The defect of the proximal tubules can be observed even at as low as $10 \%$ fructose content in diet. While a $60 \%$ fructose diet exerts a more toxic effect on the renal tubule function. Those disturbances lead to defects in uric acid excretion, as well as induction of hypercalciuria and hyperphosphaturia. Thus, fructose-induced metabolic syndrome together with supersaturation of urine with mineral salts lead to precipitation of calcium salts in the renal tubules, while concurrent inflammation predisposes to interstitial nephrocalcinosis. An interesting observation of this work is the fact that both of the tested high-fructose diets, given for an 8-week period, based on a liquid $10 \%$ FR solution or a solid $60 \%$ FR feed, were able to induce urolithiasis in rats characterized by high insulin level and hypercalciuria. Fructose-induced tubulo-interstitial injury may be connected with secondary deficiency of active vitamin D3 and disturbances in PTH production. 


\begin{abstract}
Author Contributions: Conceptualization, M.F.; methodology, M.F. and A.B. and N.S.-M. and A.S.; validation, M.F.; formal analysis, M.F. and A.B. and N.S.-M. and A.S.; investigation, M.F. and A.B. and N.S.-M. and A.S.; resources, M.F. and A.B.; data curation, M.F.; writing—original draft preparation, M.F. and N.S.-M. and A.S.; writing-review and editing, M.F. and J.M.; supervision, M.F. and J.M.; project administration, M.F.; funding acquisition, M.F. All authors have read and agreed to the published version of the manuscript
\end{abstract}

Funding: This research was funded by PDB 2021 from Nicolaus Copernicus University in Torun, Poland.

Institutional Review Board Statement: All animal procedures were performed in compliance with the National Institutes of Health Guide for the Care and Use of Laboratory Animals and approved by the Institutional Committee for Animal Welfare at Bydgoszcz (no. 13/2007 and 22/2011), in accordance with the Polish Act on Experiments on Animals (Journal of Laws 2005/33/289) and the Directive of the European Parliament No. 2003/65/EC.

Informed Consent Statement: Not applicable.

Data Availability Statement: The data presented in this study are available on request from the corresponding author.

Acknowledgments: Special thanks to Żaneta Spóz for dietetic consultation during the experiment and to Paweł Gontarek for the statistical analysis.

Conflicts of Interest: The authors declare no conflict of interest.

\title{
References
}

1. Gross, L.S.; Li, L.; Ford, E.S.; Liu, S. Increased Consumption of Refined Carbohydrates and the Epidemic of Type 2 Diabetes in the United States: An Ecologic Assessment. Am. J. Clin. Nutr. 2004, 79, 774-779. [CrossRef]

2. Johnson, R.J.; Sanchez-Lozada, L.G.; Nakagawa, T. The Effect of Fructose on Renal Biology and Disease. J. Am. Soc. Nephrol. JASN 2010, 21, 2036-2039. [CrossRef]

3. Azaïs-Braesco, V.; Sluik, D.; Maillot, M.; Kok, F.; Moreno, L.A. A Review of Total \& Added Sugar Intakes and Dietary Sources in Europe. Nutr. J. 2017, 16, 6. [CrossRef]

4. Brymora, A.; Flisiński, M.; Johnson, R.J.; Goszka, G.; Stefańska, A.; Manitius, J. Low-Fructose Diet Lowers Blood Pressure and Inflammation in Patients with Chronic Kidney Disease. Nephrol. Dial. Transplant. Off. Publ. Eur. Dial. Transpl. Assoc.-Eur. Ren. Assoc. 2012, 27, 608-612. [CrossRef]

5. Van den Berghe, G. Fructose: Metabolism and Short-Term Effects on Carbohydrate and Purine Metabolic Pathways. Prog. Biochem. Pharmacol. 1986, 21, 1-32.

6. Mäenpää, P.H.; Raivio, K.O.; Kekomäki, M.P. Liver Adenine Nucleotides: Fructose-Induced Depletion and Its Effect on Protein Synthesis. Science 1968, 161, 1253-1254. [CrossRef]

7. Kretowicz, M.; Johnson, R.J.; Ishimoto, T.; Nakagawa, T.; Manitius, J. The Impact of Fructose on Renal Function and Blood Pressure. Int. J. Nephrol. 2011, 2011, 315879. [CrossRef]

8. Nakagawa, T.; Tuttle, K.R.; Short, R.A.; Johnson, R.J. Hypothesis: Fructose-Induced Hyperuricemia as a Causal Mechanism for the Epidemic of the Metabolic Syndrome. Nat. Clin. Pract. Nephrol. 2005, 1, 80-86. [CrossRef]

9. Pokrywczynska, M.; Flisinski, M.; Jundzill, A.; Krzyzanowska, S.; Brymora, A.; Deptula, A.; Bodnar, M.; Kloskowski, T.; Stefanska, A.; Marszalek, A.; et al. Impact of Fructose Diet and Renal Failure on the Function of Pancreatic Islets. Pancreas 2014, 43, 801-808. [CrossRef]

10. Johnson, R.J.; Perez-Pozo, S.E.; Sautin, Y.Y.; Manitius, J.; Sanchez-Lozada, L.G.; Feig, D.I.; Shafiu, M.; Segal, M.; Glassock, R.J.; Shimada, M.; et al. Hypothesis: Could Excessive Fructose Intake and Uric Acid Cause Type 2 Diabetes? Endocr. Rev. 2009, 30, 96-116. [CrossRef] [PubMed]

11. Johnson, R.J.; Segal, M.S.; Sautin, Y.; Nakagawa, T.; Feig, D.I.; Kang, D.-H.; Gersch, M.S.; Benner, S.; Sánchez-Lozada, L.G. Potential Role of Sugar (Fructose) in the Epidemic of Hypertension, Obesity and the Metabolic Syndrome, Diabetes, Kidney Disease, and Cardiovascular Disease. Am. J. Clin. Nutr. 2007, 86, 899-906. [CrossRef]

12. Sánchez-Lozada, L.G.; Tapia, E.; Jiménez, A.; Bautista, P.; Cristóbal, M.; Nepomuceno, T.; Soto, V.; Avila-Casado, C.; Nakagawa, T.; Johnson, R.J.; et al. Fructose-Induced Metabolic Syndrome Is Associated with Glomerular Hypertension and Renal Microvascular Damage in Rats. Am. J. Physiol. Renal Physiol. 2007, 292, F423-F429. [CrossRef]

13. Scales, C.D.; Smith, A.C.; Hanley, J.M.; Saigal, C.S. Urologic Diseases in America Project Prevalence of Kidney Stones in the United States. Eur. Urol. 2012, 62, 160-165. [CrossRef]

14. Sas, D.J. An Update on the Changing Epidemiology and Metabolic Risk Factors in Pediatric Kidney Stone Disease. Clin. J. Am. Soc. Nephrol. CJASN 2011, 6, 2062-2068. [CrossRef]

15. Taylor, E.N.; Curhan, G.C. Fructose Consumption and the Risk of Kidney Stones. Kidney Int. 2008, 73, 207-212. [CrossRef] 
16. Koh, E.T.; Reiser, S.; Fields, M. Dietary Fructose as Compared to Glucose and Starch Increases the Calcium Content of Kidney of Magnesium-Deficient Rats. J. Nutr. 1989, 119, 1173-1178. [CrossRef]

17. Ng, H.-Y.; Lee, Y.-T.; Kuo, W.-H.; Huang, P.-C.; Lee, W.-C.; Lee, C.-T. Alterations of Renal Epithelial Glucose and Uric Acid Transporters in Fructose Induced Metabolic Syndrome. Kidney Blood Press. Res. 2018, 43, 1822-1831. [CrossRef]

18. Nguyen, N.U.; Dumoulin, G.; Henriet, M.T.; Regnard, J. Increase in Urinary Calcium and Oxalate after Fructose Infusion. Horm. Metab. Res. Horm. Stoffwechselforsch. Horm. Metab. 1995, 27, 155-158. [CrossRef]

19. Abate, N.; Chandalia, M.; Cabo-Chan, A.V.; Moe, O.W.; Sakhaee, K. The Metabolic Syndrome and Uric Acid Nephrolithiasis: Novel Features of Renal Manifestation of Insulin Resistance. Kidney Int. 2004, 65, 386-392. [CrossRef]

20. Asselman, M.; Verkoelen, C.F. Fructose Intake as a Risk Factor for Kidney Stone Disease. Kidney Int. 2008, 73, 139-140. [CrossRef]

21. Sakhaee, K.; Capolongo, G.; Maalouf, N.M.; Pasch, A.; Moe, O.W.; Poindexter, J.; Adams-Huet, B. Metabolic Syndrome and the Risk of Calcium Stones. Nephrol. Dial. Transplant. Off. Publ. Eur. Dial. Transpl. Assoc.-Eur. Ren. Assoc. 2012, 27, $3201-3209$. [CrossRef] [PubMed]

22. Siener, R. Nutrition and Kidney Stone Disease. Nutrients 2021, 13, 1917. [CrossRef] [PubMed]

23. Khan, S.R.; Glenton, P.A. Calcium Oxalate Crystal Deposition in Kidneys of Hypercalciuric Mice with Disrupted Type IIa Sodium-Phosphate Cotransporter. Am. J. Physiol. Renal Physiol. 2008, 294, F1109-F1115. [CrossRef]

24. Khan, S.R. Nephrocalcinosis in Animal Models with and without Stones. Urol. Res. 2010, 38, 429-438. [CrossRef]

25. Oron-Herman, M.; Rosenthal, T.; Sela, B.-A. Hyperhomocysteinemia as a Component of Syndrome X. Metabolism 2003, 52, 1491-1495. [CrossRef]

26. Hwang, S.-Y.; Woo, C.W.H.; Au-Yeung, K.K.W.; Siow, Y.L.; Zhu, T.Y.; Karmin, O. Homocysteine Stimulates Monocyte Chemoattractant Protein-1 Expression in the Kidney via Nuclear Factor-KappaB Activation. Am. J. Physiol. Renal Physiol. 2008, 294, F236-F244. [CrossRef] [PubMed]

27. Cirillo, P.; Gersch, M.S.; Mu, W.; Scherer, P.M.; Kim, K.M.; Gesualdo, L.; Henderson, G.N.; Johnson, R.J.; Sautin, Y.Y. Ketohexokinase-Dependent Metabolism of Fructose Induces Proinflammatory Mediators in Proximal Tubular Cells. J. Am. Soc. Nephrol. JASN 2009, 20, 545-553. [CrossRef] [PubMed]

28. Kizhner, T.; Werman, M.J. Long-Term Fructose Intake: Biochemical Consequences and Altered Renal Histology in the Male Rat. Metabolism 2002, 51, 1538-1547. [CrossRef]

29. Gersch, M.S.; Mu, W.; Cirillo, P.; Reungjui, S.; Zhang, L.; Roncal, C.; Sautin, Y.Y.; Johnson, R.J.; Nakagawa, T. Fructose, but Not Dextrose, Accelerates the Progression of Chronic Kidney Disease. Am. J. Physiol. Renal Physiol. 2007, 293, F1256-F1261. [CrossRef]

30. Nakayama, T.; Kosugi, T.; Gersch, M.; Connor, T.; Sanchez-Lozada, L.G.; Lanaspa, M.A.; Roncal, C.; Perez-Pozo, S.E.; Johnson, R.J.; Nakagawa, T. Dietary Fructose Causes Tubulointerstitial Injury in the Normal Rat Kidney. Am. J. Physiol. Renal Physiol. 2010, 298, F712-F720. [CrossRef]

31. Nakagawa, T.; Hu, H.; Zharikov, S.; Tuttle, K.R.; Short, R.A.; Glushakova, O.; Ouyang, X.; Feig, D.I.; Block, E.R.; Herrera-Acosta, J.; et al. A Causal Role for Uric Acid in Fructose-Induced Metabolic Syndrome. Am. J. Physiol. Renal Physiol. 2006, 290, F625-F631. [CrossRef]

32. Spatola, L.; Ferraro, P.M.; Gambaro, G.; Badalamenti, S.; Dauriz, M. Metabolic Syndrome and Uric Acid Nephrolithiasis: Insulin Resistance in Focus. Metabolism 2018, 83, 225-233. [CrossRef]

33. Hu, Q.-H.; Wang, C.; Li, J.-M.; Zhang, D.-M.; Kong, L.-D. Allopurinol, Rutin, and Quercetin Attenuate Hyperuricemia and Renal Dysfunction in Rats Induced by Fructose Intake: Renal Organic Ion Transporter Involvement. Am. J. Physiol. Renal Physiol. 2009, 297, F1080-F1091. [CrossRef]

34. Milne, D.B.; Nielsen, F.H. The Interaction between Dietary Fructose and Magnesium Adversely Affects Macromineral Homeostasis in Men. J. Am. Coll. Nutr. 2000, 19, 31-37. [CrossRef] [PubMed]

35. Ng, R.C.; Rouse, D.; Suki, W.N. Calcium Transport in the Rabbit Superficial Proximal Convoluted Tubule. J. Clin. Investig. 1984, 74, 834-842. [CrossRef] [PubMed]

36. Girardi, A.C.; Titan, S.M.; Malnic, G.; Rebouças, N.A. Chronic Effect of Parathyroid Hormone on NHE3 Expression in Rat Renal Proximal Tubules. Kidney Int. 2000, 58, 1623-1631. [CrossRef]

37. Binswanger, U.; Helmle-Kolb, C.; Forgo, J.; Mrkic, B.; Murer, H. Rapid Stimulation of Na $\mathrm{Na}^{+} \mathrm{H}^{+}$Exchange by 1,25-Dihydroxyvitamin D3; Interaction with Parathyroid-Hormone-Dependent Inhibition. Pflugers Arch. 1993, 424, 391-397. [CrossRef]

38. Lemann, J.; Piering, W.F.; Lennon, E.J. Possible Role of Carbohydrate-Induced Calciuria in Calcium Oxalate Kidney-Stone Formation. N. Engl. J. Med. 1969, 280, 232-237. [CrossRef] [PubMed]

39. Kohri, K.; Garside, J.; Blacklock, N.J. The Role of Magnesium in Calcium Oxalate Urolithiasis. Br. J. Urol. 1988, 61, 107-115. [CrossRef] [PubMed]

40. Li, M.K.; Blacklock, N.J.; Garside, J. Effects of Magnesium on Calcium Oxalate Crystallization. J. Urol. 1985, 133, 123-125 [CrossRef]

41. Fetner, C.D.; Barilla, D.E.; Townsend, J.; Pak, C.Y. Effects of Magnesium Oxide on the Crystallization of Calcium Salts in Urine in Patients with Recurrent Nephrolithiasis. J. Urol. 1978, 120, 399-401. [CrossRef]

42. Bergstra, A.E.; Lemmens, A.G.; Beynen, A.C. Dietary Fructose vs. Glucose Stimulates Nephrocalcinogenesis in Female Rats. J. Nutr. 1993, 123, 1320-1327. [CrossRef] [PubMed]

43. Manterys, A.; Filipiak-Florkiewicz, A.; Florkiewicz, A.; Franczyk-Zarow, M.; Kus, E.; Sady, M.; Kostogrys, R. Short-Term Feeding with High Fructose Diet Impairs Bone Mineralization in Growing Rats. Prog. Nutr. 2018, 20, 629-634. [CrossRef] 
44. Knox, F.G.; Osswald, H.; Marchand, G.R.; Spielman, W.S.; Haas, J.A.; Berndt, T.; Youngberg, S.P. Phosphate Transport along the Nephron. Am. J. Physiol.-Ren. Physiol. 1977, 233, F261-F268. [CrossRef]

45. Douard, V.; Sabbagh, Y.; Lee, J.; Patel, C.; Kemp, F.W.; Bogden, J.D.; Lin, S.; Ferraris, R.P. Excessive Fructose Intake Causes 1,25-(OH)(2)D(3)-Dependent Inhibition of Intestinal and Renal Calcium Transport in Growing Rats. Am. J. Physiol. Endocrinol. Metab. 2013, 304, E1303-E1313. [CrossRef] [PubMed]

46. Johnson, R.J.; Perez-Pozo, S.E.; Lillo, J.L.; Grases, F.; Schold, J.D.; Kuwabara, M.; Sato, Y.; Hernando, A.A.; Garcia, G.; Jensen, T.; et al. Fructose Increases Risk for Kidney Stones: Potential Role in Metabolic Syndrome and Heat Stress. BMC Nephrol. 2018, 19, 315. [CrossRef]

47. Herlitz, L.C.; D'Agati, V.D.; Markowitz, G.S. Crystalline Nephropathies. Arch. Pathol. Lab. Med. 2012, 136, 713-720. [CrossRef] 